\title{
Engineering change management in the engineer-to-order production environment: insights from two case studies
}

\author{
Natalia Iakymenko ${ }^{[0000-0001-8407-8785]}$, Anita Romsdal, Marco Semini and Jan Ola \\ Strandhagen
}

\author{
NTNU, MTP Valgrinda, S.P.Andersens vei 5, 7031, Trondheim, Norway \\ natalia.iakymenko@ntnu.no, anita.romsdalentnu.no, \\ marco.semini@ntnu.no, ola.strandhagen@ntnu.no
}

\begin{abstract}
Engineering changes (ECs) are part of any Engineer-to-order (ETO) project. The engineering change management $(\mathrm{ECM})$ literature provides various tools, methods and best practices, and this study investigates ECM practices in the ETO production environment. Through two exploratory case studies, we identify five main ECM challenges; EC impact analysis, EC data management, internal and external collaboration and communication, and EC post-implementation review. Both companies have implemented the main ECM steps recommended in literature but there are considerable weaknesses in the execution of the post-implementation review process. More ETO cases are needed to confirm the findings and investigate how ECM tools and approaches vary by different dimensions.
\end{abstract}

Keywords: Engineering change, change management, engineer-to-order.

\section{Introduction}

Engineering changes (EC) will often occur throughout the entire product life-cycle of a product [1]. ECs are modifications to structure, behaviour and function of a technical artefact that have already been released during the design process [2,3]. Such modifications can be triggered by customers, suppliers, governmental bodies, a company's internal departments, and by market drivers such as technology. A single change often causes a series of downstream changes across the company, from design and engineering departments, to supply, procurement, manufacturing and post-manufacturing stages. The implementation of engineering change management (ECM) is argued to reduce negative impacts such as cost and time overruns [3]. ECM refers to the organization, control, and execution of ECs, and covers the entire product life cycle from the selection of a concept to the wind-down of production and support [2]. The formal ECM process usually consists of the following stages: identify change, assess its impacts, implement change, and review the process [4]. For each of the stages, a number of studies have been conducted to develop support tools and methods to predict, evaluate, and control ECs [2]. Research has found that ECM varies by industrial sector [5], sug- 
gesting that the application of tools, approaches and techniques vary by production volume (one-offs versus mass production), the degree of customer involvement, the degree of internal and external uncertainty, and the inherent product complexity.

In the engineer-to-order (ETO) production environment, a product is designed, engineered and produced after a customer order has been received. Typical ETO products include ships, offshore platforms and power generation plants. Each product is typically unique and has a high level of complexity. In such production environments, ECs are common and inevitable, and ETO companies must be able to accommodate ECs throughout the project duration, even during physical production [6]. Efficient management of ECs is therefore critical to meet targets for cost, quality and schedule. The purpose of our study is therefore to perform an exploratory investigation into ECM in the ETO production environment. Two case studies were used to address the following research questions: 1) how is ECM currently performed in typical ETO companies?, and 2) what challenges do they face in their ECM? After a description of our research methodology, the paper briefly introduces the ECM topic in general and within the ETO production environment specifically. Then the main insights from the case studies are described, before the paper concludes with some general discussion and suggestions for further research.

\section{Research methodology}

In order to investigate ECM practices and challenges in the ETO production environment, an explorative case study was performed in two Norwegian ETO companies. ECM literature was used to develop an interview guide. The questions were designed firstly to map the ECM processes of the companies and secondly to identify challenges of ECM in each stage of the ECM process. The questions covered the following ECM topics: ECM procedures and activities, documentation, communication, responsibilities, and strategies and techniques at each stage. The interview guide was used to interview three representatives from Company A (two project managers and one production planner) and two representatives from Company B (project managers). The first author carried out all the interviews, and to the extent possible, the same questions were asked to all the company representatives in order to increase the reliability of the collected data. All interviews were recorded, transcribed and sent to the respective interviewees for review and confirmation. In addition, documentation from the companies' quality systems was collected, including descriptions of change management procedures, change order forms, and change evaluation sheets.

The NVivo software was used to store and analyse the case data. Descriptive codes were assigned to data chunks to detect recurring patterns in the interviews and the company documents [7]. A narrative description of the ECM processes was created, as well as a tabular listing of ECM challenges in each company. The challenges include both specific challenges mentioned by the company representatives in the interviews and challenges identified by comparing company data to ECM literature, noting when company processes, procedures, etc. deviated from practices suggested in literature. 


\section{Engineering Change Management}

A generalized model for ECM can be divided into four steps: identify change, assess its impacts, implement change, and review the process [4]. At the identification stage, a request for the change must be made and all necessary information about the change needs to be captured. Next, the impact of the EC must be assessed and the EC approved [4]. It is important to understand the effects of change propagation not only on engineering drawings, but also on the downstream activities of production, supply and procurement. The focus of previous research on EC propagation has mainly been on the engineering phase, without proper consideration of implications for the physical production phase or associated supply chain [8].

The implementation of an EC occurs immediately after it has been confirmed or it can be phased out [9]. The EC should be communicated to the affected functions as soon as possible and implemented by making the best use of resources [4]. One major problem in EC implementation is to ensure that only the current documentation is available to all functions and departments [10]. Finally, the EC should be reviewed to see if the initial estimations were correct, and the knowledge that was gained during the EC implementation process should be gathered and centrally stored for analysis and use in future EC implementations [4].

In addition to the four steps of the ECM model, various management strategies and techniques for efficient and effective ECM have been proposed. These strategies include establishment of cross-functional EC boards or committees for evaluation and approval of changes, establishment of formal change impact analysis, separate meetings and prioritization rules and principles for change assessment, concurrent crosscompany change processes with data sharing, and monitoring and controlling of ongoing engineering changes (for more on this, see Storbjerg et al. [11]).

ECM is particularly challenging in the ETO production environment. ETO products are produced in low volumes (often volumes of one), and have a deep and wide product structure [12]. Customers are involved throughout design, engineering and manufacturing, and there are virtually no constraints on the customers with respect to incorporating their individual preferences [12], often resulting in a high number of ECs. In ETO, design, engineering, manufacturing and procurement processes are often carried out almost concurrently to adhere to the delivery schedule $[13,14]$. In a make-to-stock (MTS) production environment, the EC implementation process usually takes place through a gradual product development process, where changes are accumulated and realized in the next product version [9]. This method is not applicable in the ETO environment, where ECs are introduced to the current customer order and cannot be postponed to the next order. This means that ECs can affect components that have already been manufactured, assembled, ordered from a supplier, or even delivered and installed - potentially leading to rework, demolition and even scrapping. 


\section{$4 \quad$ Findings from case studies}

\subsection{Introduction to case companies}

Case company A is a Norwegian ship production company that produces offshore support vessels (OSV) and has recently added cruise vessels to its portfolio. The company acts as ship designer, shipyard, and main equipment supplier, and delivers both highly customized and so-called catalogue vessels. For catalogue vessels, design and most parts of the engineering is done before a specific customer is known. Catalogue vessels do not allow for ECs from customers so this study focused only on the company's customized vessel segment. The delivery time for customized vessel is on average two years, and one project can experience tens or even hundreds of significant ECs.

Case company B is located in Norway and belongs to a large international industrial manufacturing firm. The company produces power electronic equipment such as propulsion systems, uninterruptible power supply (UPS) systems, and low voltage distribution systems. The product complexity and customization level varies, but all of the products are customized to some extent. The delivery time varies from 16 to 24 week, and the amount of ECs is much lower than in Company A, usually not exceeding 10 ECs per project.

\subsection{Company ECM processes}

Both the case companies use the ISO9000 standard to control the change management system. The companies' ECM procedures are described in their internal quality systems. In both companies, the ECM consists of the following steps: change identification, change evaluation, change order request to customer and change implementation. The EC process typically begins when the project manager is notified about a needed change. In response to the change requests, project manager makes a rough estimation of the EC. Depending on the size of the change and potential disciplines affected, relevant project team representatives are brought in to work on the EC. The team might consist of representatives from engineering, production, planning, and purchasing departments. Each team representative assesses the change impacts in terms of materials and person-hours required. Based on the output from the project team, the project manager creates a formal Change Order Request (COR) that is sent to the customer for confirmation. The COR describes the change and consequences such as delivery time and contract cost. Next, a dialogue with the customer takes place to achieve consent and a deadline for customer response is specified in the COR. If the customer replies to the COR after the deadline, the companies can re-evaluate it and send a revised version with a new deadline. This is done because engineering, production and procurement has progressed during this time, and the EC might therefore have bigger impacts than initially estimated. After the COR is confirmed by the customer, the relevant departments are notified about the EC, and drawings, material lists and production plans are updated in the respective IT systems.

The case companies apply the formal change process described above to large ECs initiated by customers. ECs caused by internal mistakes and errors in engineering and 
production are typically fixed locally by the affected disciplines and are consequently not documented as change orders.

\subsection{Insights on company ECM challenges}

EC impact analysis.

It is important for a company to estimate the impacts of an EC on their activities in order to make sure that there is enough time, materials and resources to implement the change in question. Both case companies emphasized that the scope of a change has a tendency to exceed what was agreed in the COR because the ECs incur bigger consequences than initially estimated. There are several reasons for this kind of erroneous EC impact estimations. Often, ECs are introduced after production has already started. The impact of adding a part or a component to a product is relatively easy to estimate. However, when an EC requires rework and demolition, estimation gets more complicated. For example, adding a new pipe to the produced vessel is relatively easy to calculate; it will consist of labour and material costs. However, if adding a new pipe involves demolition of the work previously done by e.g. electricians and carpenters, the calculation needs to include the amount of scrapped material and the person-hours used for rework. Furthermore, in production it is often difficult to identify if delays occur due to an EC or other disturbances, such as materials shortages and delivery delays.

An EC on one part of the product can propagate to other parts and components. Engineers working on changes might overlook such propagations. When unaccounted propagations pop up during production, experienced production workers are often able to find new solutions and handle issues by themselves without involving engineers, designers or managers. Although such production worker expertise is an advantage for the company, if the information on production non-conformances is not communicated upstream, it will be lost and not accounted for the next time a similar EC occurs.

Change impact assessment in both companies is based on the personal experience and expertise of the project managers and the project teams. This means that experienced managers are able to assess the impacts of ECs fairly well. However, practice has shown that their assessments can also be incorrect, indicating that the project team would likely benefit from access to support tools and methods for making more accurate estimations.

EC data management.

After an EC is confirmed, the relevant change documentation is updated, such as engineering drawings, project plans and schedules, activity and components lists, and production and purchasing plans. This documentation is updated in standalone IT systems sequentially, which takes time. This can have considerable consequences in the ETO production environment, where production is constantly progressing and the later production is notified about change, the more rework it will require. We also found that the engineering discipline coordinators in Company A do not have access to the IT planning tools. The project activity lists are exported from the planning tool to Excel spreadsheets. Each coordinator corrects the list according to the new EC. The planners 
record the updated activity lists in the planning tool manually based on the Excel lists from coordinators, leading to unnecessary information handling.

In both companies, ECs caused by mistakes and errors in engineering and production are fixed internally, and if they do not have influence on contractual specifications, they do not go through the formal ECM procedure. Hence, information about internal ECs and their impacts is not documented and not available for future use. Even though ECs caused by customer requirements are formally documented, information on such ECs changes is also not easily accessible. The project manager and project team use Excel spreadsheets and Word files to calculate impacts of ECs. These files are stored locally on the project team's PCs and are not centrally available.

Internal collaboration and communication.

In both companies, there is usually informal communication between the team representatives. Company A often holds separate meetings to discuss EC requests, while Company B reviews changes as part of weekly status meetings. The project manager decides who will be involved in the change impact assessment process. This means that disciplines not involved in the process can receive late notification. Early notification to production and purchasing about potential ECs would enable shifting production activities to other parts of the product or postponing procurement of affected parts and components to avoid rework and scrapping.

External collaboration and communication.

Communication with customers and suppliers in the companies is mainly done through e-mail and phone. Relationships with suppliers in the ETO production environment are usually established for the duration of one project, so large investments in integrated IT systems for communication does not make sense.

Some specific collaboration and communication problems were identified for Company A since they often do not have a direct relationship with all of their suppliers. For example, in one of the projects, the ship owner contracted Company A to design the vessel and contracted another shipyard to build the vessel. The customer also purchased the main engines before the project started. After the project started, the contract with the engine supplier was transferred to the shipyard. Consequently, Company A could only interact with the engine supplier through the shipyard to receive technical specifications when ECs occurred. Such a line of communication can delay information, leading to delays in the production and delivery of drawings.

Language barriers and lack of experience of external shipyards was also mentioned as a challenge by Company A when working on ECs. Often, vessels are only designed by Company A in one such project, the vessel was built by Chinese shipyard. When engineering drawings were updated due customer initiated ECs, it took several weeks to translate the drawings into Chinese. In addition, when design problems occurred during construction, the shipyard employees did not have the skills to solve them locally.

EC post-implementation review.

The main purpose of the post-implementation review is to evaluate an EC after it has been implemented, assess if the initial impact estimation was correct, identify mistakes 
made at each ECM stage and prevent similar mistakes in the future. Both companies indicated that they do not perform post-implementation reviews of ECs. They state that it is very difficult to know the impact of an EC on production even after it has been implemented. Tracking the exact number of person-hours and materials used in production for each ECs would require a lot of additional administrative work.

Summary of ECM challenges in case companies.

Table 1 summarises the challenges identified and described above.

Table 1. ECM challenges in the case companies

\begin{tabular}{|c|c|c|}
\hline ECM challenge & Description & $\begin{array}{l}\text { Com } \\
\text { pany }\end{array}$ \\
\hline \multirow{2}{*}{$\begin{array}{l}\text { EC impact analy- } \\
\text { sis }\end{array}$} & EC impact analysis is mainly based on personal experience & $\mathrm{A}, \mathrm{B}$ \\
\hline & $\begin{array}{l}\text { Difficulties in estimating impacts on production and supply chain } \\
\text { after production has started }\end{array}$ & $\mathrm{A}, \mathrm{B}$ \\
\hline \multirow[t]{3}{*}{$\begin{array}{l}\text { EC data manage- } \\
\text { ment }\end{array}$} & $\begin{array}{l}\text { Various standalone IT systems need to be updated to implement } \\
\text { an EC }\end{array}$ & $\mathrm{A}, \mathrm{B}$ \\
\hline & Internal ECs are not documented as ECs & $\mathrm{A}, \mathrm{B}$ \\
\hline & Calculations of change impact estimations are not stored centrally & $\mathrm{A}, \mathrm{B}$ \\
\hline $\begin{array}{l}\text { Internal coord. } \\
\text { and comm. }\end{array}$ & $\begin{array}{l}\text { Production and purchasing representatives are involved only after } \\
\text { an EC has been approved }\end{array}$ & A, B \\
\hline \multirow[t]{3}{*}{$\begin{array}{l}\text { External coord. } \\
\text { and comm. }\end{array}$} & $\begin{array}{l}\text { Communication with customers and suppliers is done by e-mail } \\
\text { and phone }\end{array}$ & A, B \\
\hline & No direct communication with some suppliers & A \\
\hline & Language barriers and lack of experience of third-party suppliers & A \\
\hline $\begin{array}{l}\text { EC post-imple- } \\
\text { mentation review }\end{array}$ & No post-implementation review process & $\mathrm{A}, \mathrm{B}$ \\
\hline
\end{tabular}

\section{$5 \quad$ Conclusions and further research}

This study has provided some insights into ECM practices and challenges in the ETO production environment. The exploratory study showed that both case companies have implemented the main ECM steps recommended in literature into their formal ECM processes. However, both cases showed considerable weaknesses in the execution of the post-implementation review, where neither company is using available documentation on historic ECs to predict, estimate or avoid future ECs. In addition, internally generated ECs are not documented, thus the company cannot analyse their frequency, nature and impact to learn and avoid similar problems in the future. The high reliance on employees experience and expertise in the management of ECs further means that the companies are highly vulnerable to employee turnover or absenteeism. In the future, we will add more case studies to confirm the findings from the study. Further, we plan to use the dimensions of Eckert et al. (2009) [5] to analyse the cases on differences in ECM tools and approaches with regards to product complexity, degree of customer involvement, degree of internal and external uncertainty, etc.

While challenges such as data management, collaboration, impact analysis, etc. are common for all types of industries (as was shown in previous research), the propagation 
of ECs to the manufacturing and procurement processes is especially important in the ETO production environment. Hence, there is a need to study such propagations in more detail, as well as develop appropriate ECM tools and techniques to support in the ECM process.

\section{References}

1. Morris, A., Halpern, M., Setchi, R., and Prickett, P.: Assessing the challenges of managing product design change through-life. Journal of Engineering Design 27(1-3), pp. 25-49 (2016).

2. Hamraz, B., Caldwell, N.H., and Clarkson, P.J.: A holistic categorization framework for literature on engineering change management. Systems Engineering 16(4), pp. 473-505 (2013).

3. Jarratt, T., Clarkson, J., and Eckert, C.: Engineering change. Design process improvement, pp. 262-285 (2005).

4. Jarratt, T., Eckert, C.M., Caldwell, N.H., and Clarkson, P.J.: Engineering change: an overview and perspective on the literature. Research in engineering design 22(2), pp. 103124 (2011).

5. Eckert, C., Clarkson, J., de Weck, O., and Keller, R.: Engineering change: drivers, sources, and approaches in industry. In Proceedings of ICED 09, the 17th International Conference on Engineering Design, Vol. 4, Product and Systems Design, Palo Alto, CA, USA. (2009).

6. Semini, M., Haartveit, D.E.G., Alfnes, E., Arica, E., Brett, P.O., and Strandhagen, J.O.: Strategies for customized shipbuilding with different customer order decoupling points. Proceedings of the Institution of Mechanical Engineers, Part M: Journal of Engineering for the Maritime Environment, pp. 362-372 (2014).

7. Miles, M.B., Huberman, A.M., and Saldana, J.: Qualitative data analysis. Sage (2013).

8. Iakymenko, N., Romsdal, A., Strandhagen, J.O., and Semini, M.: Managing engineering changes in engineer-to-order environment: challenges and research needs. In IFAC Symposium on Information Control Problems in Manufacturing (INCOM 2018). Italy (2018).

9. Nadia, B., Gregory, G., and Vince, T.: Engineering change request management in a new product development process. European Journal of Innovation Management 9(1), pp. 5-19 (2006).

10. Wright, I.: A review of research into engineering change management: implications for product design. Design Studies 18(1), pp. 33-42 (1997).

11. Storbjerg, S.H., Brunoe, T.D., and Nielsen, K.: Towards an engineering change management maturity grid. Journal of Engineering Design 27(4-6), pp. 361-389 (2016).

12. Stavrulaki, E. and Davis, M.: Aligning products with supply chain processes and strategy. The International Journal of Logistics Management 21(1), pp. 127-151 (2010).

13. Han, J., Lee, S.-H., and Nyamsuren, P.: An integrated engineering change management process model for a project-based manufacturing. International Journal of Computer Integrated Manufacturing 28(7), pp. 745-752 (2015).

14. Bertrand, J. and Muntslag, D.: Production control in engineer-to-order firms. International Journal of Production Economics 30, pp. 3-22 (1993). 